\title{
JUKMAS
}

Jurnal Untuk Masyarakat Sehat (JUKMAS)

e-ISSN : 2715-7687

Vol. 4, No. 1 April 2020

P-ISSN : 2715-8748

\section{Faktor-Faktor Yang Berhubungan Dengan Pemanfaatan Senam Lansia Di Posyandu Flamboyan Desa Bandulu Kecamatan Anyar Banten Tahun 2018}

\author{
Yuliana, Izattul Azijah \\ Fakultas IImu Kesehatan Universitas Respati Indonesia \\ Email : yuliana_yull67@gmail.com
}

\begin{abstract}
ABSTRAK
Kematian terbanyak lansia dikarenakan penyakit degeneratif. Dari beberapa upaya menjaga kesehatan dan pencegahan penyakit bagi lansia, senam merupakan tindakan yang banyak dianjurkan. Senam bagi lansia memiliki gerakan-gerakan yang sederhana dengan tempo lambat dan waktu yang diperlukan juga singkat sehingga tenaga yang dikeluarkan tidak terlalu besar. Penelitian ini bertujuan untuk mengetahui faktor-faktor yang berhubungan dengan pemanfaatan senam lansia. Penelitian ini menggunakan pendekatan kuantitatif dengan rancangan cross sectional. Instrumen yang digunakan dalam penelitian ini menggunakan kuesioner. Populasi dalam penelitian ini seluruh lansia yang datang ke posyandu Flamboyan berjumlah 210 responden. Sampel penelitian ini dengan menggunakan cara accidental sampling sebanyak 68 orang. Berdasarkan hasil dari penelitian univariat menunjukkan sebagian besar pemanfaatan senam lansia kategori rutin sebanyak 35 orang $(51,5 \%)$, sebagian besar pengetahuan lansia tentang kegiatan senam lansia yang berkategori kurang baik sebanyak 40 orang $(58,8 \%)$, sebagian besar pendidikan lansia terhadap senam lansia yang berkategori rendah yaitu sebanyak 53 orang $(77,9 \%)$ dan sebagian besar dukungan keluarga yang berkategori mendukung yaitu sebanyak 36 orang $(52,9 \%)$. Hasil bivariat menunjukkan ada hubungan antara pengetahuan, pendidikan, dan dukungan keluarga. Tidak ada hubungan antara jenis kelamin dengan pemanfaatan senam lansia di Posyandu Flamboyan Desa Bandulu Kecamatan Anyar Banten 2018. Bagi posyandu diharapkan meningkatkan pelayanan senam lansia dengan menambah posyandu bagi responden yang jauh dan selalu memberikan informasi kepada lansia atau keluarga untuk mengikuti senam lansia.
\end{abstract}

Kata kunci : Senam lansia, pengetahuan, pendidikan, dukungan keluarga, jenis kelamin

\begin{abstract}
Most elderly deaths due to degenerative diseases. From several efforts to maintain health and prevent disease for the elderly, gymnastics is a recommended action. Gymnastics for the elderly has simple movements with a slow tempo and the time required is also short so that the energy expended is not too large. This study aims to determine the factors associated with the use of elderly gymnastics. This research uses a quantitative approach with cross sectional design. The instrument used in this study used a questionnaire. The population in this study all the elderly who came to the Posyandu Flamboyan amounted to 210 respondents. The sample of this study was 68 accidental sampling methods. Based on the results of univariate research, the majority of routine elderly gymnastic use is 35 people (51.5\%), most of the elderly's knowledge about elderly
\end{abstract}


gymnastics activities are categorized as poor as 40 people $(58.8 \%)$, most of the elderly's education towards Low category of elderly exercise is 53 people $(77.9 \%)$ and most of the family support that is categorized supports 36 people (52.9\%). Bivariate results show there is a relationship between knowledge, education, and family support. There is no relationship between sex with the use of elderly gymnastics in the Flamboyan Posyandu in Bandulu Village, Anyar Banten District 2018. The posyandu is expected to improve elderly gymnastics services by adding posyandu for distant respondents and always providing information to the elderly or families to attend elderly gymnastics.

Keywords : elderly exercise, knowledge, education, family support, gender

\section{PENDAHULUAN}

Keberhasilan pembangunan dalam menurunkan angka kematian dan kelahiran berdampak pada perubahan struktur penduduk. Semula, penduduk didominasi oleh kelompok muda, namun berkat kemajuan ilmu pengetahuan dan teknologi di bidang kesehatan, telah memberikan implikasi yang cukup besar dimasa depan, yaitu semakin meningkatnya angka harapan hidup (life expectancy); semakin banyak penduduk yang mampu bertahan hidup, maka berimplikasi terhadap peningkatan jumlah penduduk usia tua atau lanjut usia (lansia). ${ }^{1}$

Tahun 2010 World Health Organization mencatat dari 675 juta kematian lansia didunia dikarenakan penyakit degeneratif, 225 juta (proporsi 33,33\%) berada di negara maju dan 450 juta (proporsi 66,66) berada di negara berkembang. Prevalensi kematian lansia karena penyakit degeneratif di beberapa negara berkembang di asia tenggara pada tahun 2008, yaitu Vietnam mencapai 65,5\%,
Thailand mncapai 61\%, Myanmar mencapai 57,1\%, Malaysia 72\%, Filiphina mencapai 66,2\%, Singapura mencapai $78,6 \%$ dan di Indonesia pada 63,1\% kematian lansia dari keseluruhan angka kematian yaitu 650 juta jiwa. ${ }^{2}$

Indonesia termasuk salah satu negara yang jumlah penduduk lansia bertambah paling cepat di Asia Tenggara. Perkiraan bertambahnya jumlah lansia di Indonesia, dalam kurun waktu tahun 1990 - 2025, tergolong tercepat di dunia. ${ }^{3}$

Di Indonesia terdapat 10 propinsi yang berstruktur tua dengan presentase lanjut usianya lebih dari 7 persen. yaitu Daerah Istimewa Yogyakarta, Jawa Timur, Jawa Tengah, Bali, Sulawesi Selatan, Sumatera Barat, Sulawesi Utara, Nusa Tenggara Barat, Jawa Barat dan Nusa Tenggara Timur. Dari keseluruhan lansia yang ada hampir 90\% lansia di Indonesia tidak menerapkan olahraga senam lansia. ${ }^{3}$

Menurut Peraturan Pemerintah Republik Indonesia Nomor 43 tahun 2004, lanjut usia adalah seseorang yang telah 
mencapai usia 60 (enam puluh) tahun ke atas. Komposisi penduduk tua bertambah dengan pesat baik di negara maju maupun negara berkembang, hal ini disebabkan oleh penurunan angka fertilitas (kehamilan) dan mortalitas (kematian), serta peningkatan angka harapan hidup (life expectancy), yang mengubah struktur penduduk secara keseluruhan. Proses terjadinya penuaan penduduk dipengaruhi oleh beberapa faktor, misalnya: peningkatan gizi, sanitasi, pelayanan kesehatan, hingga kemajuan tingkat pendidikan dan sosial ekonomi yang semakin baik. ${ }^{4}$

Saat ini struktur penduduk Indonesia mengalami perubahan menuju masyarakat yang lebih banyak lansia. Berdasarkan data Badan Pusat Statistik (BPS) tahun 2015, Indonesia memiliki 21,68 juta jiwa penduduk lansia $(8,49 \%$ dari keseluruhan penduduk) dan menurut hasil proyeksi penduduk tahun 2010-2035 menunjukkan bahwa Indonesia akan mengalami peningkatan jumlah lansia mencapai $10 \%$ di tahun $2020 .^{5}$

Berdasarkan data proyeksi penduduk, diperkirakan tahun 2017 terdapat 23,66 juta jiwa penduduk lansia di Indonesia (9,03\%). Diprediksi jumlah penduduk lansia tahun 2020 (27,08 juta), tahun 2025 (33,69 juta), tahun 2030 (40,95 juta) dan tahun $2035(48,19$ juta). Suatu negara dikatakan berstruktur tua jika mempunyai populasi lansia di atas tujuh persen. ${ }^{4}$

Seiring dengan meningkatnya jumlah lansia, maka semakin tinggi pula permasalahan kesehatan yang dialami oleh lansia tersebut. Seperti yang diungkapkan oleh Heriawan Soejono dan Divisi Geriatri Departemen Penyakit Dalam FKUI "salah satu masalah penting yang dihadapi para lansia adalah kesehatan". Berbagai masalah kesehatan yang dialami oleh lansia terjadi karena proses penuaan dan hal ini biasa disebut sebagai penyakit degeneratif. $^{8}$

Penyakit degeneratif merupakan penyakit kronik menahun yang banyak mempengaruhi kualitas hidup serta kualitas seseorang. Penyakit degeneratif terjadi karena adanya proses penuaan biasanya terjadi saat usia bertambah tua. Penyakit dengeneratif itu sendiri meliputi Hipertensi, obesitas, diabetus militus, reumatik, Osteoporosis, dan penyakit jantung. Angka kematian lansia dengan penyakit degeneratif di Asia masih tergolong tinggi, tahun 2008 mencapai 42 $\%$ dari keseluruhan kematian yang mencapai 650 ratus ribu untuk setiap satu juta jiwa. Itu artinya angka kematian lansia dengan penyakit degenetatif mencapai 273 ratus ribu jiwa. Prediksi pada tahun 2015 proporsi tersebut akan meningkat 3-5\% dari angka keseluruhan kematian, Itu 
artinya dari 650 ratus ribu kematian akan bertambah sebanyak 666,5 ratus ribu.

Meningkatnya penyakit degeneratif dan masalah-masalah kesehatan pada lansia salah satunya di karenakan kurangnya menjaga kesehatan. Upaya yang dapat dilakukan dalam mengatasi masalahmasalah yang terjadi sebagai akibat dari perubahan yang dialami lansia salah satunya yaitu perawatan diri sehari-hari, senam atau latihan pergerakan secara teratur, makan-makanan bergizi, dan pemeriksaan kesehatan secara rutin. ${ }^{6}$

Pencegahan penyakit pada usia lanjut meliputi upaya prevensi primer, sekunder, daan tersier. Dalam kategori pencegahan primer, tindakan-tindakannya meliputi menghentikan merokok, latihan atau olahraga teratur, dan imunisasi atau suntikan pencegahan infeksi. ${ }^{7}$

Dari beberapa upaya menjaga kesehatan dan pencegahan penyakit bagi lansia, senam merupakan tindakan yang banyak dianjurkan. Senam bagi lansia memiliki gerakan-gerakan yang sederhana dengan tempo lambat dan waktu yang diperlukan juga singkat sehingga tenaga yang dikeluarkan tidak terlalu besar. Hasil penelitian menunjukkan bahwa lansia dengan keterlibatan sosial yang lebih besar memiliki semangat dan kepuasan hidup yang lebih tinggi, penyesuaian serta kesehatan mental lebih positif daripada lansia yang kurang terlibat secara sosial. ${ }^{8}$
Kurangnya olahraga pada lansia disebabkan karena lansia tidak termotivasi dari dalam dirinya sendiri untuk melakukan olahraga senam lansia, sebagian besar lansia akan melakukan olahraga senam lansia jika sudah didorong oleh keluarganya, dan tenaga kesehatan untuk melaksanakan olahraga senam lansia. Senam lansia memiliki efek realaksasi, menguatkan jantung, otot, persendian, tulang rawan serta mengencangkan otot kaki. Aktivitas olahraga senam lansia ini akan membantu tubuh tetap bugar dan segar karena melatih tulang tetap kuat, mendorong jantung bekerja optimal, dan membantu menghilangkan radikal bebas yang berkeliaran di dalam tubuh. Rendahnya motivasi dalam melakukan olahraga senam lansia disebabkan oleh faktor kesehatan lansia, factor usia, pengetahuan, pendidikan, herediter, faktor lingkungan, faktor fasilitas, program dan aktifitas, audio visual, sertas situasi dan kondisi lansia. ${ }^{6}$

Berdasarkan data yang didapatkan dari rekam medik Puskesmas Anyar Jumlah Lansia Pada Tahun 2017 ada sebanyak 2.119 orang dan jumlah lansia di Posyandu Flamboyan Desa Bandulu Kecamatan Anyar Banten sebanyak 210 orang.

Berdasarkan Studi Pendahuluan yang dilakukan oleh peneliti di Posyandu Flamboyan Desa Bandulu Kecamatan Anyar Kabupaten Serang Banten dari 10 
responden, sebanyak 3 orang yang rutin dalam mengikuti senam lansia, sedangkan 7 orang tidak pernah mengikuti senam lansia yang dilaksanakan setiap 4 kali/bulan dan jadwal setiap hari minggu. Data ini menunjukkan bahwa masih sedikit lansia yang mengikuti kegiatan senam lansia dengan alasan tempat senam terlalu jauh dan masih banyak lansia yang belum mengetahui manfaat dari senam lansia serta kurangnya dukungan dari keluarga dalam melakukan senam lansia.

Berdasarkan uraian latar belakang di atas maka penulis merasa tertarik untuk meneliti lebih dalam mengenai "FaktorFaktor Yang Berhubungan Dengan Pemanfaatan Senam Lansia di Posyandu Flamboyan Desa Bandulu Kecamatan Anyar Banten".

\section{METODE}

Penelitian ini merupakan jenis penelitian deskriptif kuantitatif dengan menggunakan metode penelitian cross sectional (potong lintang). Penelitian cross sectional adalah suatu penelitian dimana variabel-variabel yang termasuk faktor resiko dan variabel yang termasuk efek diobservasi sekaligus pada waktu yang sama. ${ }^{9}$

Hasil yang diharapkan yaitu
diketahuinya hubungan antara pengetahuan, pendidikan, dukungan keluarga, jarak dan jenis kelamin dengan pemanfaatan senam lansia. Penelitian ini dilaksanakan di Desa Bandulu Kecamatan Anyar Banten. Penelitian ini akan dilaksanakan pada bulan Mei-Agustus 2018. Populasi pada penelitian ini adalah semua lansia baik laki-laki dan perempuan yang tinggal di Desa Bandulu Kecamatan Anyar Banten yang berjumlah 210 orang. Dalam penelitian ini tekhnik sampling yang digunakan adalah dengan cara tekhnik accidental sampling yaitu pengambilan sampel dengan cara assidental dengan mengambil kasus atau responden yang kebetulan ada atau tersedia disuatu tempat dengan konteks penelitian. ${ }^{10}$ Sampel dalam penelitian ini sebanyak 68 orang. Jenis data yang digunakan dalam penelitian ini adalah data primer, data primer adalah data yang diperoleh langsung dari responden dan Data primer dalam penelitian ini adalah seluruh lansia yang berkunjung ke Posyandu Flamboyan di Desa Bandulu Serang Banten.

\section{HASIL}

Tabel 1. Hasil Analisis Univariat

\begin{tabular}{lcc}
\hline Variabel & $\mathbf{n}$ & \% \\
\hline Pemanfaatan Senam Lansia & & \\
\hline Tidak Rutin & 33 & 48,5 \\
Rutin & 35 & 51,5 \\
\hline Pengetahuan & & \\
\hline Kurang & 40 & 58,8 \\
Baik & 28 & 41,2 \\
\hline Pendidikan & & \\
\hline Rendah & 53 & 77,9 \\
Tinggi & 15 & 22,1 \\
\hline Dukungan Keluarga & & \\
\hline Tidak Mendukung & 32 & 47,1 \\
Mendukung & 36 & 52,9
\end{tabular}




\begin{tabular}{|c|c|c|c|c|c|c|c|c|c|}
\hline \multicolumn{4}{|c|}{ Jenis Kelamin } & \multicolumn{4}{|c|}{ Perempuan } & \multicolumn{2}{|c|}{$40 \quad 58,8$} \\
\hline \multicolumn{2}{|c|}{ Laki - laki } & & & & & & & & \\
\hline \multirow{3}{*}{ No } & \multirow{3}{*}{ Variabel Penelitian } & \multicolumn{4}{|c|}{ Pemanfaatan Senam Lansia } & \multirow{2}{*}{\multicolumn{2}{|c|}{ Total }} & \multirow{3}{*}{$\begin{array}{l}P \\
\text { value }\end{array}$} & \multirow{3}{*}{$\begin{array}{l}\text { OR } \\
(95 \% \mathrm{Cl})\end{array}$} \\
\hline & & \multicolumn{2}{|c|}{ Tidak Rutin } & \multicolumn{2}{|c|}{ Rutin } & & & & \\
\hline & & $\mathbf{n}$ & $\%$ & $\mathbf{n}$ & $\%$ & $\mathbf{n}$ & $\%$ & & \\
\hline \multirow[t]{3}{*}{1} & Pengetahuan & & & & & & & \multirow{3}{*}{0,000} & 25,000 \\
\hline & Kurang Baik & 30 & 75 & 10 & 25 & 40 & 100 & & $6,195-$ \\
\hline & Baik & 3 & 10,7 & 25 & 89,3 & 28 & 100 & & 100,886 \\
\hline \multirow[t]{3}{*}{2} & Pendidikan & & & & & & & \multirow{3}{*}{0,005} & \multirow{3}{*}{$\begin{array}{l}9,159 \\
1,876-44,726\end{array}$} \\
\hline & Rendah & 31 & 58,5 & 22 & 53 & 53 & 100 & & \\
\hline & Tinggi & 2 & 13,3 & 13 & 15 & 15 & 100 & & \\
\hline \multirow[t]{3}{*}{3} & Dukungan Keluarga & & & & & & & \multirow{3}{*}{0,000} & 77,333 \\
\hline & Tidak Mendukung & 29 & 90,6 & 3 & 9,4 & 32 & 100 & & $15,944-$ \\
\hline & Mendukung & 4 & 11,1 & 32 & 88,9 & 36 & 100 & & 375,089 \\
\hline \multirow[t]{3}{*}{4} & Jenis Kelamin & & & & & & & & \\
\hline & Laki-laki & 13 & 46,4 & 15 & 53,6 & 28 & 100 & \multirow{2}{*}{0,965} & 0,867 \\
\hline & Perempuan & 20 & 50 & 20 & 50 & 40 & 100 & & $0.329-2,280$ \\
\hline
\end{tabular}

4. PEMBAHASAN

\section{a. Perilaku Pemanfaatan Senam Lansia di} Posyandu Flamboyan Desa Bandulu Kecamatan Anyar Banten Tahun 2018

Perilaku merupakan respon atau reaksi seseorang terhadap stimulus atau rangsangan dari luar perilaku juga dapat diartikan sebagai suatu tindakan atau perbuatan yang dapat diamati dan dipelajari (Notoatmodjo, 2012). ${ }^{14}$ Berdasarkan hasil penelitian menunjukkan pemanfaatan senam lansia kategori tidak rutin sebanyak 33 orang $(48,5 \%)$, sedangkan sebagian besar pemanfaatan senam lansia kategori rutin sebanyak 35 orang (51,5\%).

Hasil penelitian sebelumnya pernah dilakukan Nadia Puspitasari,
Bagoes Widjanarko, Suroto 2017 (Jurnal Kesehatan Masyarakat) tentang FaktorFaktor Yang Berhubungan Dengan Pemanfaatan Senam Lansia Di Posyandu Kelurahan Sendangmulyo, Kota Semarang menyebutkan bahwa lansia yang memanfaatkan senam lansia sebesar 26 (41,3\%), sedangkan lansia yang tidak memanfaatkan senam lansia sebesar $37(58,7)$. Keadaan ini mencerminkan bahwa perilaku lansia terhadap pemanfaatan senam lansia masih cenderung relative rendah. ${ }^{11}$

Dari hasil penelitian di Posyandu Flamboyan Desa Bandulu Kecamatan Anyar Kabupaten Serang Banten diperoleh keterangan bahwa mereka tidak melakukan senam lansia karena hal tersebut dipengaruhi oleh faktor 
pengetahuan, pendidikan, dukungan keluarga dan jarak.

b. Hubungan Antara Pengetahuan dengan Pemanfaatan Senam Lansia di Posyandu Flamboyan Desa Bandulu Kecamatan Anyar Banten Tahun 2018

Berdasarkan hasil analisis hubungan antara pengetahuan dengan pemanfaatan senam lansia diperoleh bahwa ada sebanyak 30 responden (75\%) lansia yang berpengetahuan kurang baik yang tidak rutin melakukan senam lansia dan ada sebanyak 10 responden $(25 \%)$ yang rutin melakukan senam lansia. Sedangkan diantara lansia yang berpengetahuan baik, ada 3 responden $(10,7 \%)$ yang tidak rutin melakukan senam lansia dan ada sebanyak 25 responden $(89,3 \%)$ yang rutin melakukan senam lansia.

Hasil uji Chi Square di peroleh nilai $p$ value $=0,000$ dengan demikian $p$ value kurang dari alpha $(0,05)$ yang artinya secara statistik ada hubungan yang signifikan antara pengetahuan dengan pemanfaatan senam lansia.

Hasil penelitian ini sejalan dengan penelitian sebelumnya yang dilakukan oleh Veronica Wulan Widyastuti (2011), tentang Hubungan Tingkat Pengetahuan Tentang Senam Lansia Dengan Keaktifan Mengikuti Senam Lansia Di Unit Rehabilitas Sosial Wening Wardoyo Ungaran, menyebutkan bahwa nilai signifikansi $p=0,002$ dan nilai koefisien korelasi sebesar 0,435, Artinya ada hubungan antara tingkat pengetahuan tentang senam lansia dengan keaktifan mengikuti senam lansia dengan arah hubungan positif dan kekuatan hubungan tingkat sedang. ${ }^{12}$

Hasil penelitian ini tidak sejalan dengan hasil penelitian sebelumnya yang dilakukan oleh Nadia Puspitasari, Bagoes Widjanarko, Suroto (2017) (Jurnal Kesehatan Masyarakat) tentang Faktor-Faktor Yang Berhubungan Dengan Pemanfaatan Senam Lansia Di Posyandu Kelurahan Sendangmulyo, Kota Semarang. Hasil penelitian sebelumnya menyebutkan bahwa banyak ditemukan pada lansia berpengetahuan baik $(46,2 \%)$ dan nilai $p$-value 0,689 $>0,05$ sehingga tidak ada hubungan antara pengetahuan dengan pemanfaatan senam lansia. ${ }^{11}$

Pengetahuan merupakan hasil tahu dan ini terjadi setelah orang melakukan penginderaan terhadap suatu obyek tertentu. Penginderaan terjadi melalui panca indera manusia, yakni: indera penglihatan, pendengaran, penciuman, rasa dan raba. Sebagian besar pengetahuan manusia diperoleh melalui mata dan telinga. $^{9}$ 
Berdasarkan uraian diatas peneliti berasumsi, didapatkan bahwa pengetahuan merupakan salah satu faktor pendorong seseorang untuk merubah perilaku atau mengadopsi perilaku baru. Pengetahuan tentang pemanfaatan senam lansia merupakan faktor yang menentukan lansia dapat merubah perilaku negatif dalam mencari pelayanan tentang senam lansia ke perilaku positif.

c. Hubungan Antara Pendidikan dengan Pemanfaatan Senam Lansia di Posyandu Flamboyan Desa Bandulu Kecamatan Anyar Banten 2018

Berdasarkan hasil analisis
hubungan antara pendidikan dengan
pemanfaatan senam lansia diperoleh
bahwa ada sebanyak 31 responden
(58,5\%) lansia yang berpendidikan
rendah yang tidak rutin melakukan
senam lansia dan ada sebanyak 22
responden (41,5\%) yang rutin
melakukan senam lansia . Sedangkan
diantara lansia yang berpendidikan
tinggi, ada 2 responden (13,3\%) yang
tidak rutin melakukan senam lansia dan
ada sebanyak 13 responden (86,7\%)
yang rutin melakukan senam lansia.
Berdasarkan Hasil uji statistik di
peroleh nilai $p$ value = 0,005 dengan
demikian $p$ value kurang dari alpha
(0,05) yang artinya secara statistik ada
hubungan yang signifikan antara


pemanfaatan senam lansia dan semakin rendah tingkat pendidikan lansia maka semakin rendah perilaku lansia. Tingkat pendidikan secara langsung merupakan salah satu faktor yang ikut mempengaruhi dalam pemanfaatan senam lansia ke posyandu. Dalam hal ini pendidikan tidak bisa diintervensi secara langsung oleh sektor kesehatan, oleh sebab itu diperlukan informasi melalui pendidikan kesehatan seperti penyuluhan sehingga dengan diberikannya pengetahuan tentang manfaat senam lansia, walaupun dengan pendidikan rendah akan membantu keefektifan peningkatan jumlah lansia untuk datang ke posyandu lansia tetapi bila tidak diwujudkan secara nyata untuk datang ke posyandu lansia tetap saja tidak memberikan pengaruh bagi perkembangan kunjungan ke posyandu lansia.

d. Hubungan Antara Dukungan Keluarga dengan Pemanfaatan Senam Lansia Di Posyandu d. Flamboyan Desa Bandulu Kecamatan Anyar Kabupaten Serang Banten Tahun 2018

Berdasarkan hasil analisis hubungan antara dukungan keluarga dengan pemanfaatan senam lansia diperoleh bahwa ada sebanyak 29 responden $(90,6 \%)$ keluarga yang tidak mendukung lansia dalam melalukan senam lansia yang tidak rutin melakukan senam lansia dan ada sebanyak 3 responden $(9,4 \%)$ yang rutin melakukan senam lansia. Sedangkan diantara keluarga yang mendukung lansia dalam melakukan senam lansia ada sebanyak 4 responden $(11,1 \%)$ yang tidak rutin melakukan senam lansia dan ada sebanyak 32 responden $(88,9 \%)$ yang rutin melakukan senam lansia.

Berdasarkan hasil uji statistik diperoleh nilai $p$ value $=0,000$ dengan demikian $p$ value kurang dari alpha $(0,05)$ yang artinya secara statistik ada hubungan yang signifikan antara dukungan keluarga dengan pemanfaatan senam lansia.

Hasil penelitian ini sejalan dengan penelitian yang di lakukan oleh Vivin Novarina (2012) dengan judul “ Hubungan dukungan keluarga tentang senam lansia dengan keaktifan mengikuti senam di posyandu "peduli insani" di mendungan desa pabelan kartasura", menunjukkan bahwa ada hubungan yang signifikan antara dukungan keluarga dengan pemanfaatan senam lansia. ${ }^{15}$

Hasil penelitian ini sejalan dengan penelitian yang dilakukan oleh Lambok Elisabet Sitohang (2016), tentang Faktor-Faktor Yang Memengaruhi Pemanfaatan Posyandu Lansia Di Wilayah Kerja Puskesmas Securai 
Kecamatan Babalan Kabupaten Langkat menyebutkan didapatkan nilai $p=0,000$ $<0,05$ yang artinya ada hubungan yang signifikan antara dukungan keluarga dengan pemanfaatan posyandu lansia. Berdasarkan hasil penelitian hubungan jarak dengan pemanfaatan posyandu lansia menunjukkan bahwa dari 70 orang yang jarak jauh terdapat 5 orang $(7,1 \%)$ yang memanfaatkan posyandu lansia dan yang tidak memanfaatkan posyandu sebanyak 65 orang $(92,9 \%)$, sedangkan dari 60 orang yang jarak dekat terdapat 10 orang $(16,7 \%)$ yang memanfaatkan posyandu lansia dan yang tidak memanfaatkan posyandu sebanyak 50 orang $(83,3 \%) .{ }^{16}$

Berdasarkan uraian diatas maka peneliti berasumsi bahwa semakin baik perilaku lansia terhadap senam lansia maka semakin banyak lansia mendapatkan informasi dan dukungan keluarga tentang senam lansia dan semakin kurang informasi dan dukungan keluarga terhadap senam lansia maka lansia kurang mendapat informasi tentang senam lansia. Sehingga terdapat pengaruh antara perilaku lansia terhadap senam lansia dengan dukungan keluarga di Desa Bandulu Kecamatan Anyar Kabupaten Serang Banten tahun 2108.

Hal ini dikarenakan keluarga tidak mengetahui informasi tentang kegiatan posyandu lansia dan manfaat posyandu lansia sehingga kurang memotivasi lansia untuk mengikuti kegitan rutin ini. Selain itu dapat juga karena keluarga tidak memahami tujuan pelayanan kesehatan di posyandu lansia yang sebenarnya. Kurangnya dukungan sosial dapat terjadi dari anggota keluarga seperti anak, istri ataupun suami yang tinggal bersama lansia. Kurangnya dukungan ini terjadi karena anak menganggap bahwa kegiatan posyandu kurang bermanfaat. Anak responden berpendapat bahwa lebih baik orang tua jika melakukan pemeriksaan kesehatan datang ke rumah sakit atau dokter karena pemahaman mereka posyandu lansia hanyalah wadah pengobatan umum saja. Selain itu anggota keluarga mempunyai kesibukan tersendiri sehingga tidak dapat menyediakan waktu khusus untuk menemani dan mendampingi orangtuanya mengikuti posyandu lansia.

e. Hubungan Antara Jenis Kelamin dengan Pemanfaatan Senam Lansia Di Posyandu Flamboyan Desa Bandulu Kecamatan Anyar Kabupaten Serang Banten Tahun 2018

Berdasarkan hasil penelitian ini menunjukan bahwa ada sebanyak 13 responden (46,4\%) lansia yang 
berjenis kelamin laki-laki yang tidak rutin melakukan senam lansia dan ada 15 responden $(53,6 \%)$ yang rutin melakukan senam lansia. Sedangkan lansia yang berjenis kelamin perempuan ada sebanyak 20 responden (50\%) lansia yang tidak rutin mengikuti senam lansia, dan ada sebanyak 20 responden (50\%) lansia yang rutin melakukan senam lansia.

Hasil uji Chi Square di peroleh nilai $p$ value $=0,965$ dengan demikian $p$ value lebih besar dari alpha $(0,05)$ yang artinya secara statistik tidak ada hubungan yang signifikan antara jenis kelamin dengan pemanfaatan senam lansia.

Hasil penelitian ini sejalan dengan hasil penelitian sebelumnya yang dilakukan oleh Nadia Puspitasari, Bagoes Widjanarko, Suroto (2017) (Jurnal Kesehatan Masyarakat) tentang Faktor-Faktor Yang Berhubungan Dengan Pemanfaatan Senam Lansia Di Posyandu Kelurahan Sendangmulyo, Kota Semarang. Hasil penelitian ini menyebutkan bahwa hasil bivariat pada variabel jenis kelamin ditemukan bahwa lansia yang memanfaatkan senam lansia lebih banyak pada lansia berjenis kelamin perempuan $(51,5 \%)$ dan nilai $p$-value $0,140>0.05$ sehingga tidak ada hubungan antara jenis kelamin dengan pemanfaatan senam lansia. ${ }^{11}$

Berdasarkan uraian diatas maka peneliti berasumsi bahwa jenis kelamin laki-laki dan perempuan tidak ada hubungan dengan pemanfaatan senam lansia hal tersebut dikarenakan, lansia laki-laki lebih jarang untuk mengikuti kegiatan senam lansia. Ketidakaktifan lansia laki-laki dalam kegiatan senam lansia dapat disebabkan oleh faktor malas, malu, dan tidak ada yang menginisiasi untuk rutin hadir di kegiatan senam lansia. Secara keaktifan khususnya dalam aktivitas fisik, lansia laki-laki dapat lebih aktif daripada lansia perempuan dikarenakan mereka lebih sehat dan lebih mampu mempertahankan gaya hidup secara fisik. Namun secara sosial, perempuan lebih memiliki kepuasan dalam berpartisipasi di kegiatan keolahragaan atau kemasyarakatan.

\section{Simpulan d}

a. Pemanfaatan Senam Lansia di Posyandu Flamboyan Desa Bandulu Kecamatan Anyar Kabupaten serang Banten sebagian besar melakukan senam lansia sebanyak 35 responden (51,5\%) dan yang tidak melakukan senam lansia sebanyak 33 responden $(48,5 \%)$. 
b. Ada hubungan antara pengetahuan, pendidikan, dukungan keluarga dengan pemanfaatan senam lansia di Posyandu Flamboyan Desa Bandulu Kecamatan Anyar Kabupaten serang Banten.

c. Tidak ada hubungan antara jenis kelamin dengan pemanfaatan senam lansia di di Posyandu Flamboyan Desa Bandulu Kecamatan Anyar Kabupaten serang Banten.

\section{DAFTAR PUSTAKA}

1. Departemen Sosial RI 2009. Petunjuk Teknis Bantuan Kesejahteraan Sosial Pada Panti Jompo Milik Masyarakat. Departemen Sosial RI, Jakarta

2. Sugiyono. 2014. Metode Penelitian Kuantitatif, Kualitatif Dan $R \& D$. Bandung: ALFABETA, CV

3. Riskesdes. 2012. Badan Penelitian Dan Pembangunan Kesehatan Kementrian RI Tahun 2012. Diakses 16 april 2018

4. Depkes RI. Laporan Hasil Riset Kesehatan Dasar Indonesia Tahun 2017. Jakarta. Badan Penelitian Dan Pengembangan Kesehatan Depkes Rl; 2017
5. Badan Pusat Statistik. 2015. Statistik Penduduk Lanjut Usia 2014, Jakarta: Badan Pusat Statistik

6. Narendra, M.S, dkk. 2013. Mengenal Penyakit Pada Lanjut Usia. Jakarta: Pustaka Sinar Harapan

7. Darmojo. 2009. Buku Ajar Geriatri. Jakarta : Balai Penerbit FKUI.

8. Potter, Perry. 2010. Fundamental Of Nursing : Consep Proces And Practice. Edisi 7. Vol 3. Jakarta : EGC

9. Notoatmodjo, 2012. Metodologi Penelitian kesehatan, jakarta: Rineka Cipta.

10. Notoatmodjo, 2010. IImu Kesehaatan Masyarakat PrinsipPrinsip Dasar. Jakarta: Rineka Cipta

11. Puspitasari. 2017. Faktor-Faktor Yang Berhubungan Dengan Pemanfaatan Senam Lansia Di Posyandu Kelurahan Sendangmulyo, Kota Semarang. Diakses pada tanggal 23 Februari 2018

12. Widyastuti. 2011. Hubungan Tingkat Pengetahuan Tentang Senam Lansia Dengan Keaktifan Mengikuti Senam Lansia Di Unit Rehabilitasi Sosial Wening Wardoyo Ungaran. Diakses pada tanggal 08 Agustus 2018

13. Alhidayati. 2013. Faktor-faktor yang Berhubungan dengan Perilaku 
Kunjungan Lansia ke Posyandu Lansia di Kerja Puskesmas Kampar Kabupaten Kampar. Diakses pada tanggal 04 Agustus 2018

14. Sukmawati. 2015. Faktor yang berhubungan dengan perilaku lansia dalam memanfaatkan posyandu lansia di wilayah kerja Puskesmas Landono Kabupaten Konawe Selatan. Diakses pada tanggal 04 Agustus 2018

15. Novarina. 2012. Hubungan Dukungan Keluarga tentang Senam
Lansia Dengan Keaktifan Mengikuti Senam Di Posyandu "Peduli Insani" di Mendungan Desa Pabelan Kartasura. Diakses 16 April 2018

16. Sitohang. 2016. Faktor-Faktor Yang Memengaruhi Pemanfaatan Posyandu Lansia Di Wilayah Kerja Puskesmas Securai Kecamatan Babalan Kabupaten Langkat. Diakses pada tanggal 16 April 2018 